\title{
Trends in Prosthodontics
}

\author{
Gunnar E. Carlsson $^{\mathrm{a}}$ Ridwaan Omar ${ }^{\mathrm{b}}$ \\ a Department of Prosthetic Dentistry, Göteborg University, Göteborg, Sweden; \\ ${ }^{b}$ Department of Restorative Sciences, Faculty of Dentistry, Kuwait University, Kuwait
}

\section{Key Words \\ Prosthetic dentistry - Edentulism - Removable partial dentures - Complete dentures - Fixed partial dentures · Dental implants $\cdot$ Shortened dental arch concept}

\begin{abstract}
Prosthodontics is concerned with the impact of tooth or tissue damage and partial or complete loss of teeth on oral function in its broadest sense. It deals with this largely through prosthetic replacement. The discipline occupies a major portion of a dental school curriculum, and dental practitioners usually devote much of their practice to prosthodontic services. With the rapid improvement in oral health and the reduction of edentulism in many countries, increasing numbers of people are retaining more teeth later in life. Gradually, the main focus in prosthodontics has shifted from removable dentures to fixed prostheses, while implant-supported restorations have attracted intense interest in the dental community. Another factor increasingly influencing prosthodontic practice is patients' awareness of newer technologies in aesthetic dentistry. Because prosthodontic interventions as well as maintenance and repair are by nature costly, the global development in the field manifests fundamental inequalities in the levels of service that patients can
\end{abstract}

access. Diminishing resources for health care in general challenges educators and practitioners of prosthodontics alike. This review is an attempt to describe the recent developments in prosthodontics and its therapeutic areas, and the impact such developments may have on the theory and practice of the discipline.

Copyright $(2) 2006$ S. Karger AG, Basel

\section{Introduction}

Prosthodontic treatment of depleted, damaged dentitions varies widely, but the replacement of missing teeth and/or tooth structure has traditionally been at its core $[1,2]$. This statement conveys two convictions: a belief that reconstituting dental arch integrity will result in a therapeutic benefit to the patient, and an expectation that the mechanical characteristics of the prosthodontic intervention selected can positively influence treatment outcomes.

It is hardly surprising then that published definitions of prosthodontics consistently present a marked technological perspective of the discipline [3]. Arguably the most commonly used definition of prosthodontics is 'that branch of dentistry pertaining to the restoration and maintenance of oral function, comfort, appearance and

\begin{tabular}{ll}
\hline KARGER & ( ) 2006 S. Karger AG, Basel \\
Fax +4161306 1234 & 1011-7571/06/0153-0167\$23.50/0 \\
$\begin{array}{l}\text { E-Mail karger@karger.ch } \\
\text { www.karger.com }\end{array}$ & $\begin{array}{l}\text { Accessible online at: } \\
\text { www.karger.com/mpp }\end{array}$
\end{tabular}


health of the patient by the replacement of missing teeth and contiguous tissues with artificial substitutes' [4]. Notwithstanding its wide acceptance, there are those who would regard the omission in the definition of any reference to the level of oral function, comfort, appearance and health as too loose, and thus clearly problematic. Is it, for example, the ideal, the maximal or the acceptable oral function that is being sought in a given situation [5]? Furthermore, regarding the replacement of missing teeth, there is no qualification of its preferred extent, but rather a sine qua non is assumed. At the same time, risks may be associated both with and without prosthodontic intervention.

A more comprehensive definition of the discipline was advanced in a recent article, i.e. "prosthodontics is the discipline of dentistry concerned with the consequences of congenital absence or acquired loss of oral tissues and with the methods for and assessment whether more good than harm is done by inserting artificial devices made from alloplastic materials' [3]. This definition is more comprehensive than most others by focusing both on the consequences of a reduction of oral tissues as well as the outcome of modifying such conditions instead of emphasizing only the technical aspects of the discipline. Furthermore, it takes into account the tendency that dentists have to assess their patients' treatment needs on the basis of morphological considerations. Dentists frequently assess needs at higher, more interventional levels than patients, illustrating the gap between need and demand. Also, because dentists seem predisposed to operate within prosthodontic subdisciplinary boundaries that reflect particular technical characteristics (e.g. complete dentures, removable partial dentures, fixed partial dentures and implant-supported prostheses), mechanical considerations and possibilities can become the focus of treatment, inhibiting the important diagnostic phase of the process.

Despite the lack of scientific support for a 'mechanical-functional' linkage, prosthodontics has nevertheless successfully used the approach to achieve profound improvements in the quality of life for patients [6]. Conversely, high cost and a host of other barriers to treatment [7] deprive most people, except a fortunate few, of anything other than perfunctory care, if any at all.

In addition to inaccessibility brought about by, for example, factors such as economic inequalities, changes in patterns of dental disease and tooth loss are giving rise to an increasing number of older adults remaining partially dentate for a longer span of time [8, 9]. In industrialized countries, the retained teeth of these individuals have more restorations, which are often large and complex and require time as well as advanced skills to maintain [10]. The argument is compelling that change is needed in the way treatment is delivered to reflect this emerging reality [11]. Resolving such a challenge will need a joint effort from the dental profession and society, since traditional prosthodontic strategies for managing such a problem would seem to be both unattainable and inappropriate at the population level.

In light of current knowledge, this article attempts to sketch possible future developments in prosthodontics and its treatment areas, and the possible impact on prosthodontic education and literature.

\section{Recent History and Current Trends}

Any kind of prognostication needs to be based on current realities. As far as they are known, these are complex. Prosthodontics has evolved from many years of clinical experience, into what may be considered to be an expense-related hierarchy of prosthodontic treatment options [6], an approach that may be reinforced by the way it is still taught in many dental schools around the world. A problem with this form of professional development is that it is based on anecdotal experience, widely regarded as the weakest form of clinical evidence. In view of the historical background, therefore, it would be useful to begin the process of predicting future trends by briefly reminding ourselves of recent and current developments in the discipline.

Traditionally, dentistry's approach to reversing any threats to the integrity of the dentition has been through the application of prosthodontic solutions in the belief that a loss of arch intactness would result in a reduction in oral health and function. Such a therapeutic rationale gave rise to the '28-tooth syndrome', which dictated the need for complete dental arches, i.e. 28 teeth, 14 in each arch [1]. Accordingly, for many years, much of prosthodontic research focused on optimizing technology for fabricating prostheses (fig. 1).

The traditional prescription of removable partial dentures to restore partial edentulism has been increasingly questioned in the last two decades. Among the reasons are poor treatment results through increased risks for carious and periodontal damage to the remaining dentition. It has also been convincingly shown, especially with respect to mandibular distal extension situations, that no contribution to occlusal stability was gained through the use of removable partial dentures, and that there was no 


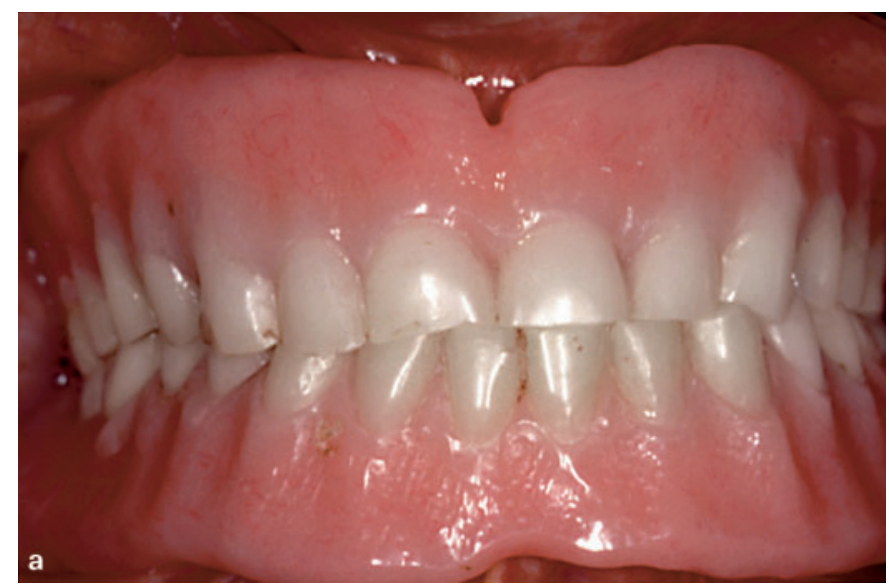

Fig. 1. Prosthodontic devices. a Maxillary and mandibular complete dentures. b Mandibular removable partial denture of a distal extension design (occlusal view). c Full-arch maxillary metal-ceramic fixed partial denture on telescopic copings, in the same patient as in $\mathbf{b}$ (right lateral excursive view).

continuing periodontal breakdown without their use as long as any pre-existing periodontal condition had been treated $[12,13]$.

Fixed prostheses are more favourably accepted by patients, but they also incur short- and longer-term biological costs, notably caries at retainer margins and other lesions of abutment teeth, as well as carrying the risk of technical complications such as loss of retention and fracture of superstructure. A recent systematic review reported longevity data for conventional fixed partial dentures, with approximately $90 \%$ surviving beyond 10 years and $75 \%$ beyond 15 years [14], although a more rapid decline in survival may occur after 20 years [15]. This can be compared to a $50 \%$ survival rate over 10 years for metal framework-based and one over 3 years for acrylic resin removable partial dentures [16]. However, given the large number of other factors that determine their prescription, it would be unrealistic to infer the relative cost-effectiveness of the fixed versus removable prosthodontic modalities from such broad data [5].
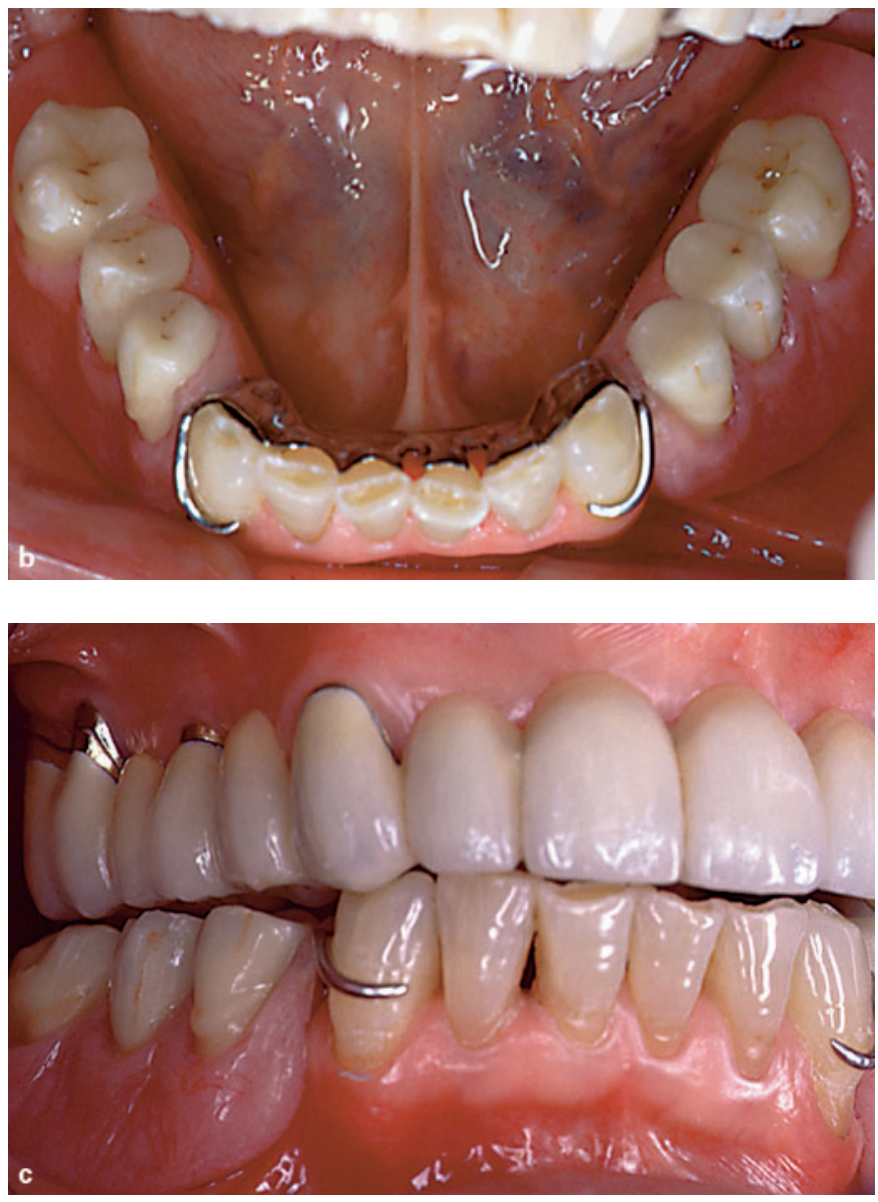

Nevertheless, until modern dental implants were introduced, people with too few remaining natural teeth and those with none had to rely on removable dentures. In less than 25 years, the principle of osseo integrated implants has revolutionized the treatment of partially and totally edentulous patients $[17,18]$ (fig. 2). Both the impact and the reality of the modality have since made implant dentistry the fastest growing field in the prosthodontic literature [19]. Historically, oral implants are alleged to have had a long past, as evidenced by several 'finds' of ancient dental implants. Published in Nature in 1998 and accorded some serious commentary by several prosthodontists, a spectacular discovery in France of an iron implant has, however, been suggested to be no more than the speculations of some 20th century archaeologists [20]. Regardless of earlier attempts at implants, it was the principle of osseo integration that launched the intensive development of implants in dentistry in 1965, which has since revolutionized the treatment of edentulous patients $[21,22]$. 

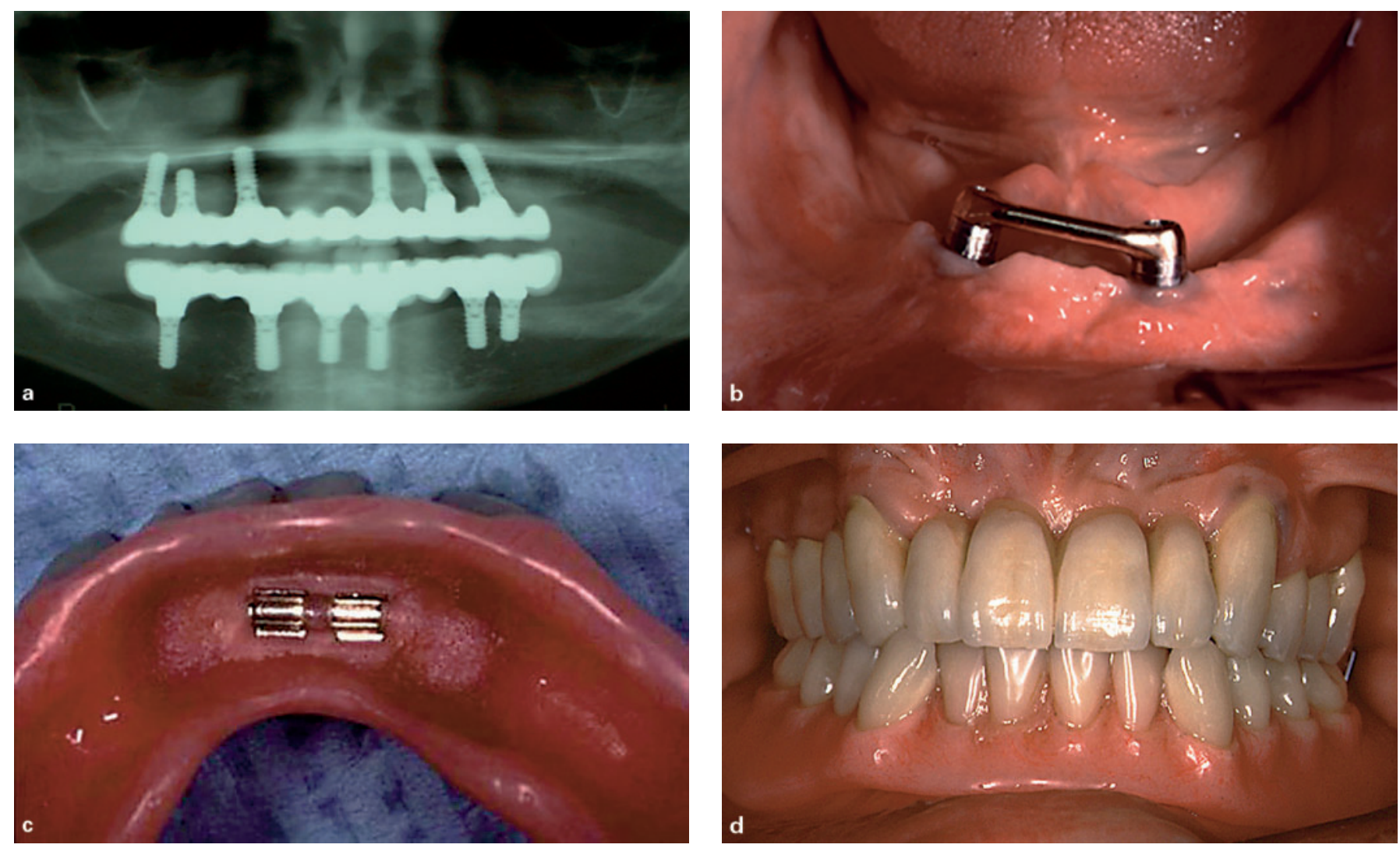

Fig. 2. Implant prostheses. a Panoramic radiograph showing maxillary and mandibular full-arch fixed implantsupported prosthesis (courtesy of Dr. Riyadh Akeel, Riyadh, Saudi Arabia). b Implant-supported bar for mandibular overdenture. c Retaining clips located in overdenture. d Overdenture in the patient's mouth together with a maxillary full-arch metal-ceramic fixed partial denture on telescopic copings (courtesy of Dr. Tariq Abduljabbar, Riyadh, Saudi Arabia).

\section{Management Trends}

Prosthodontics continues to be one of the major components of dental school curricula, and dental practitioners have usually devoted much of their clinical time to various types of prosthodontic treatment. Traditionally it has been held that the loss of teeth will lead to functional, aesthetic and often pathological sequelae in the masticatory system and a disturbance of the dental occlusion. A central goal of prosthodontics is to stabilize the occlusion and restore oral function, an approach that has enjoyed success due to the wide range of treatment possibilities available for oral rehabilitation. However, more sophisticated methods are expensive, limiting their use to relatively few patients. Cost as a constraint for treatment is evident from a global perspective of poverty, but a reality also in the wealthiest countries, where many people cannot afford high-cost dental treatment [23].

\section{Reassessing the Traditional Management Strategy}

As with treatment outcomes, treatment needs assessments for chronic diseases, disabilities and conditions (including that of tooth loss) have customarily been made on the basis of the expectations and beliefs of health care providers [24]. Yet, the scientific evidence for the validity of a number of such normative measures as the importance of arch integrity to occlusal stability, chewing ability and prevention of temporomandibular disorders is at best tenuous [25]. Increasingly there is the recognition that the professional attitude towards an individual's need must be tempered by an acceptance that it cannot be absolutely defined, either objectively or subjectively [26].

Whenever feasible, the ideal of a healthy, complete natural dentition must remain. However, for social, dental or financial reasons, this might neither be attainable nor indeed necessary [27]. Because prosthodontic therapy 
is intrinsically expensive with an inherent biological price and a finite life-span, it is increasingly recognized that a perspective broader than the normative one is required, specifically one that includes patients' perceptions, attitudes and expectations regarding the planned treatment $[6,25]$. How this web of factors interrelates to permit alternative solutions for partial edentulism remains to be explored [26]. Only by approaching treatment from this broader perspective might greater congruence between dentist- and patient-perceived needs be achieved, thus developing more appropriate responses to a populationwide management of partial edentulism. It is suggested that this is one of the key challenges facing the profession in general and prosthodontic education and practice in particular.

\section{Epidemiology and Demographics}

The prevalence of edentulism is declining in most countries and very rapidly in industrialized ones $[8,9]$. These declines are seemingly indicative of a decrease in the number of edentulous people in need of complete dentures. Indeed, for three European countries (Finland, Sweden and the UK) for which detailed information on the rate of edentulism is available, it is clear that the need for complete denture production will fall despite changing age demographics. Such falling rates are large enough to markedly affect future patterns of treatment provision as well as education and training [28].

This trend, however, may not be occurring everywhere. Recent analyses combining epidemiological and demographic data indicate that the number of people in the USA who need complete dentures will demonstrably increase over the first two decades of the 21 st century despite an anticipated decline in the rate of edentulism of approximately $10 \%$ per decade [29]. It is expected that the large increase in the number of elderly individuals will counteract the declining prevalence of edentulism and so produce the anticipated net increased requirement for complete dentures by 2020. A lack of reliable epidemiological and demographic data precludes predictions about future developments in the area of prosthodontic care provision for other countries.

\section{Implications of Declining Prevalence of \\ Edentulousness}

In spite of declines in edentulousness, there are still millions of edentulous people worldwide who need appropriate treatment, and the great majority of them will have to rely on complete dentures. Providing patients with complete dentures will, therefore, continue to be an important prosthodontic task for many more decades.

This has implications for under- and postgraduate dental education, specialist training as well as for research in the future. While it is easy to assume that the decline in edentulousness implies a reduced need for emphasis on learning skills in complete denture prosthodontics, the reality is more complex, with effects felt both at the level of dental practice and undergraduate training. Dental schools in many countries have reported difficulties in finding suitable undergraduate teaching material, while in the future, dentists in practice are likely to see too few cases to maintain their skills and confidence, let alone to develop them. An evolving situation can be envisaged in which the increasing complexity of many such cases, coupled with the growing reluctance of people to join the ranks of the edentulous, may make a large proportion of cases very challenging to manage. Dentists may become increasingly uncomfortable about treating such 'difficult denture' cases, and their management may be transferred to the minority of dentists who maintain a sufficient level of interest in this area of prosthodontics to retain a specific expertise therein [9].

\section{The Growing Partially Dentate, Older Cohort}

Improvements in oral health also mean that people keep more of their teeth in older age. These older people will ask for removable partial dentures or fixed prostheses and seek more regular dental care than complete denture wearers have $[8,30]$. In Germany as well as in Japan, it has been estimated that there will be no decrease in the demand for prosthodontic treatment until 2020 because the number of partially dentate people will increase [31]. In the UK, 96\% of adults are expected to be at least partially dentate by 2028 [9], a trend similar to many other countries.

\section{Disparities in Oral Health}

The challenges for prosthodontics are further aggravated by differences in oral health that exist both among [32] and within countries $[8,11]$. Tooth loss is not solely a function of disease, but also reflects socio-economic conditions, individual and cultural differences and access to oral health care [33,34], with economic disparities disadvantaging low-income groups [35-39]. Furthermore, differences in oral health status have frequently been explained along racial lines [34, 40], yet may be more realistically viewed in the context of underlying social and behavioural disparities resulting from structural conditions in society [41]. 
Thus, health care planning that focuses exclusively on genetic and biological determinants of health, leaving the social and societal determinants unaffected would be less than valid at the population level. So too would be the implications for a prosthodontic management strategy that targets the replacement of missing teeth per se. Among the growing numbers of middle-aged and older partially dentate patients, such a strategy is neither attainable, affordable nor necessary for the majority of patients, even in industrialized countries [7, 13, 27, 30]. For those in less developed countries, such an approach is even more unrealistic and indicates a need to reposition management goals and outcome measures accordingly.

Clearly, a healthy, complete natural dentition must remain an oral health care ideal. Yet when constraints apply, priorities need to be set. The WHO has adopted the maintenance of 20 functioning teeth without the need for a prosthesis as an oral health goal [42]. While there is much individual variation in the minimum number of teeth required for adequate function, the 20-tooth threshold is valid at the population level [13]. Thus, strategies aimed at meeting such a functional target deserve due consideration.

\section{Shortened Dental Arch Concept}

One of the most significant developments to have influenced prosthodontic thinking in the past few decades was the introduction of the shortened dental arch (SDA) concept [12]. This concept that seemingly flies in the face of the paradigm of dental arch integrity was first met with much scepticism by prosthodontists, but has with time become acknowledged as a possible option in the management of certain conditions. The SDA concept, which also dovetails with WHO guidelines [42], classically consists of 20 occluding teeth (all upper and lower incisors, canines and premolars). In practice, it may be regarded as a dentition with a reduction of teeth starting posteriorly. Patients can be managed either 'actively' or 'passively' with the SDA approach: the former variation means intentionally shortening the dental arches through extraction of badly broken-down molars to simplify an otherwise complex treatment plan and focusing attention and resources on the anterior and premolar teeth. The latter variation allows for an evaluation period for replacement of molars that have been recently or long since extracted, pending monitoring and evaluation of oral function [13]. While the 'active' application of the SDA concept aims to simplify or exclude complex treatment plans for par- ticular patients, the 'passive' approach recognizes that an individual's subjective demand could in the future necessitate molar replacements [43].

A recent review concluded that the long-standing professional belief in full reconstitution of reduced dental arches per se as a prerequisite for optimal oral health and function lacks compelling scientific support [25]. In industrialized countries, and more recently in a developing country context as well, a considerable volume of circumstantial evidence confirms that reduced posterior dental arch lengths provide oral function and comfort, maintain occlusal stability with only minor risks of incurring changes over long periods of time, do not increase the risk of temporomandibular disorders, and produce occlusal wear patterns and alveolar bone levels that are similar to those in complete dental arches [13, 44-46].

In complex treatment plans, the SDA approach offers the alternative of less treatment that is also less complicated, time-consuming and expensive. Results have not been demonstrated as inferior to those of the full-scale reconstructive approach. Indeed, as regards accepted prosthodontic reconstructive methods, there is no conclusive evidence on the relative merits of the variously recommended methods of occlusal reconstruction, for the superiority of one occlusal scheme over another [47] or for the superiority of technically sophisticated methods over simpler ones [48].

\section{Prosthodontics in the Context of Oral Health Care Policy}

Inequalities in access to and provision of health care are related to socio-economic factors that vary both among and within countries. Even in the USA, large sections of the population have low incomes, precluding any expensive dental treatment. It has recently been estimated that about one third of the US population is impoverished, either below the 'federal poverty level' $(14 \%)$ or belong to the so-called working poor (20\%) [49]. It is clear that extensive political and economic changes are necessary to improve this situation in the USA, as well as in other parts of the world with similar or often far worse conditions.

\section{A Primary Health Care Framework}

On the grounds of cost alone, the solution of the inequality problem seems not to lie in an expansion or perpetuation of traditional dental services along the lines of industrialized countries. Their history has shown that merely 
increasing the capacity of conventional dentistry does not control oral diseases [50]. What is needed is a reorientation of the oral health care system to one that meets the principles of primary health care, first expounded at the Alma Ata Conference in 1978 [51]. The fundamental principles of primary health care are the basis of an oral health care system that makes equitable use of existing health care infrastructure and applies appropriate, as opposed to sophisticated, technology with an emphasis on community-oriented prevention directed to all at an affordable price. This approach does not imply a lowering of standards or a departure from scientific principles, but rather a redefinition of the norms by which adequate oral health care for a given population is measured and evaluated.

Considering the future of prosthodontics within a primary health care framework, it might be reasonable to suggest that a 'low-tech' management strategy such as the SDA concept could amply meet the criterion of appropriate technology. Some insight into the sustainability of an SDA dentition may be gained from the fact that, in many populations, tooth decay and tooth loss occur in the molar regions $[45,52]$. This natural history of patterns of partial edentulism dovetails with the 'passive' approach to management within the SDA concept and supports the contention that the anterior and premolar teeth seem to be 'natural survivors' of the dentition. It would be a matter of more definitive research findings, however, to enable an endorsement of the 'active' approach to management. However, to perform strict, randomised controlled trials in this area would hardly be possible both from an ethical and a practical point of view.

\section{Organisational Aspects of Prosthodontics}

\section{Global Perspective}

Prosthodontics, as a discipline, shows great variation around the world with respect to its organization of teaching, clinical practice and degrees of specialization and/or competencies. In the academic domain, it can vary from large departments of prosthodontics responsible for removable, fixed, maxillofacial and implant prosthodontics, at times even including related disciplines such as dental materials, operative dentistry, oral function/dysfunction and gerodontology, to smaller units comprising only a particular subdivision of the discipline, e.g. solely removable prosthodontics. In some schools, prosthodontics has all but disappeared in name, and the subject is included in departments that are variously named, such as operative dentistry or oral rehabilitation.
Almost universally, the bulk of prosthodontic treatment offered to the public is by general dental practitioners. In many countries there are also prosthodontics specialists with additional postgraduate training, of 3 years' duration on average, but the ratio of specialists to the total number of dentists in different countries varies considerably. A further level at which prosthodontic services can be provided exists in a few countries where denturists or clinical dental technicians are licensed to provide complete dentures to edentulous patients [5].

A very large part of prosthodontic treatment involves the indirect fabrication of restorations and prostheses, which is performed by dental technicians working in laboratories with widely varying levels of infrastructural sophistication. These members of the oral health care team are indispensable to a properly functioning service, and their input forms a critical part of the quality of the clinical end-product, including aesthetics as well as serviceability of the prosthesis. There are substantial variations across countries in the training schemes that exist for dental technicians, as well as in the ratio of dental technicians per dentist, emphasizing again the anomalies with regard to the provision of prosthodontic services.

\section{Educational Trends}

The main focus in prosthodontics has shifted from removable to fixed partial dentures and implant-supported prostheses - indeed, more rapidly so in dental practice than in dental schools. It would seem obvious that dental schools should, under such conditions, have a more flexible curriculum that is adaptable to such changes. However, strongly entrenched traditions and conservatism tend to hinder our attitudes to change. Nevertheless, as a consequence of reduced undergraduate exposure to complete denture experience, appropriate postgraduate training in this field needs to be strengthened.

\section{Trends in the Prosthodontic Literature}

From a Medline search using the term 'prosthodontics', almost 70,000 articles were produced, of which approximately 10,000 were published after January 1, 2000 [19]. Even though closer scrutiny of these publications revealed many to be only weakly associated with prosthodontics, it gives an impression of the abundance of written contributions related to the specialty. Dividing the total material into four decades beginning in 1965 indicates that growth in the literature on conventional prosthodontics was rapid in the 1960s, reaching a peak in the 1990s, after which a gradual decrease occurred (fig. 3). The publications on removable prostheses were most nu- 
Fig. 3. Number of articles in 5 prosthodontic subject areas in 10-year periods from 1965. CD = Complete dentures; RPD = removable partial dentures; FPD = fixed partial dentures; $\mathrm{P}+\mathrm{I}=$ prosthodontics and dental implants; TMD = temporomandibular disorders. Modified from Carlsson [19].

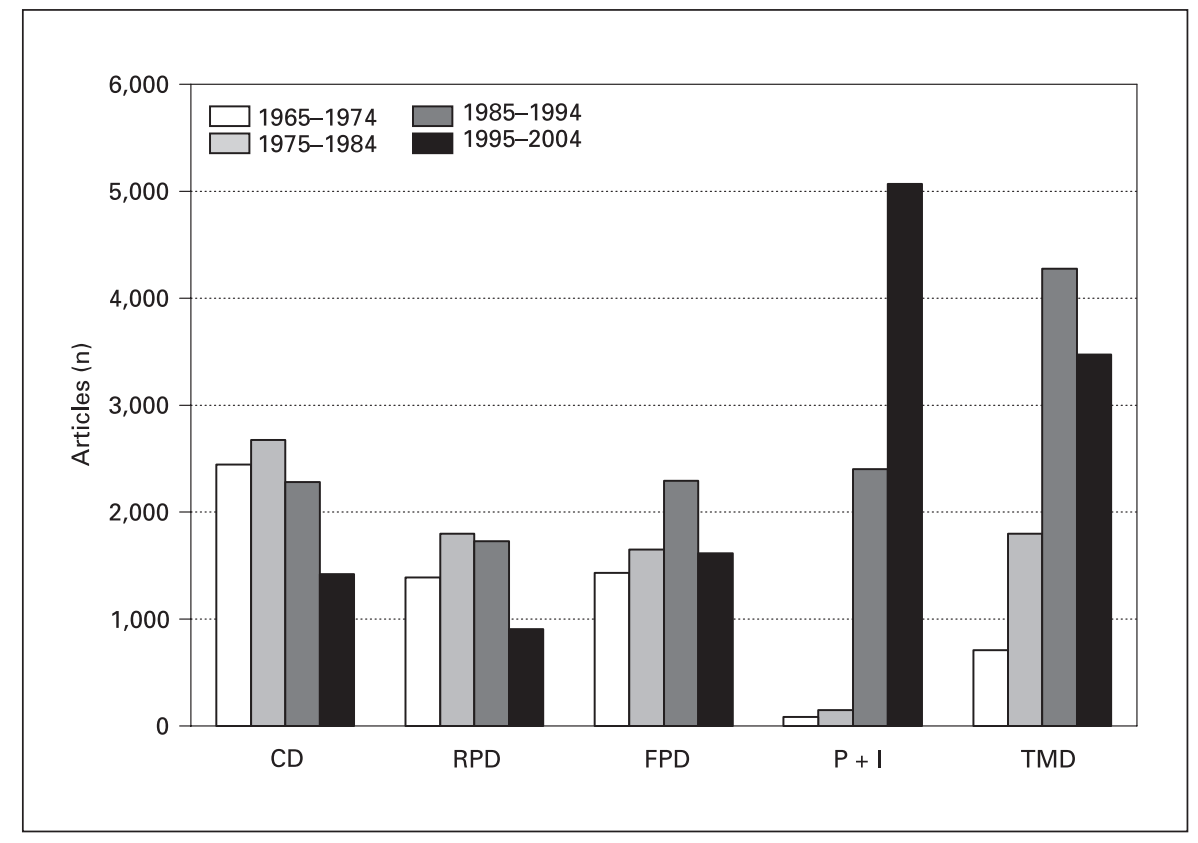

merous between 1975 and 1984 after which a substantial decrease occurred. The number of publications on implant prosthodontics, while minuscule up to 1985 , increased dramatically thereafter and compensated for the decline in other areas. The literature related to temporomandibular disorders was copious between 1985 and 1994, when it comprised 4,275 articles, but has subsequently diminished somewhat. The number of clinical studies showed a steady increase from less than $1 \%$ of all prosthodontic articles during the first decade (19651974 ) to $12 \%$ during the last decade examined (19952004).

An extensive review of prosthodontic studies up to the end of 2000 identified 92 to be randomized controlled trials covering a wide spectrum of study hypotheses, topics and issues within various domains [53]. The authors' harsh judgment was that, in general, reports were of poor methodological quality. This has resulted in a general lack of reliable evidence on a number of commonly performed prosthodontic procedures, e.g. in matters such as differences between impression materials, casting alloys, cements, occlusal adjustment, ceramics, temporization etc.

The situation is not very different in implant dentistry. More than 220 implant brands produced by about 80 manufacturers have been identified on the market, each claiming superiority for its own products. A review assessing the evidence for relationships between character- istics of dental implants and clinical performance concluded that the scientific literature did not provide any clear guidance on the alleged benefits of any specific morphological characteristics of dental implants [54].

\section{Contemporary Therapeutic Trends}

During the last few decades, there have been wideranging changes in dental care, materials and methods, which have greatly impacted dental practice in general, not least prosthodontics. For example, improvements in preventive dentistry and dental health have enhanced the prognosis of prosthodontic therapy, while new ceramic systems and adhesive materials have helped to meet rapidly increasing patient demands for more aesthetic and metal-free restorations. While the market- and consumerdriven demand for aesthetic and cosmetic dentistry may well be financially rewarding for the dental profession, it arouses varying reactions among colleagues. It is felt by some that the dearth of discussion of related ethical, conceptual and value aspects of this market-driven trend away from oral health care and towards concerns about body image threatens, or at the very least is at odds with, our professional obligations $[55,56]$.

High-tech treatment alternatives, to which implant overdentures still seem to belong, may remain restricted to countries with high per capita incomes. Hopes for its routine prescription are far removed from the reality of the rest of the world, and therefore from the majority of 
edentulous patients [23], resulting in the coining of the term 'appropriatech', i.e. prosthodontics for the many, not just for the few. The phrase is most likely derived from 'appropriate technology', which was described in the Alma Ata Primary Health Care document of 1978, and is a timely reminder of the inordinate amount of time that seems to have to pass for such 'self-evident' concepts to gain wider recognition [51]. The concept implies cost-effective conventional treatment but with adequate quality control, and a project has been undertaken to devise a minimum acceptable protocol, in this case for the fabrication of complete dentures, which will conform to generally accepted prosthodontic principles [57].

\section{Future Trends}

Attempting to forecast anything is inherently a risky undertaking. Twenty-five years ago it was unlikely that many prosthodontists could have dreamt of the fantastic possibilities that dental implants would offer to help people who had lost teeth, ranging from complete loss to just a single tooth. During the last two decades an explosion of clinical, teaching and research activities have elevated oral implants to the rank of top priority in many areas of restorative dentistry. Implant topics are an ever-increasing part of dental conferences, especially those on prosthodontics, oral surgery and periodontics. There seems to be little indication that this enormous interest will abate in the near future.

\section{Clinical Prosthodontics}

The huge scientific development described above contrasts starkly with the clinical reality: most clinical prosthodontic work performed worldwide is still of the conventional type - crowns, small fixed prostheses and removable dentures. It has recently been estimated that only $1.5 \%$ of teeth being replaced in the USA are implants, the rest being replacements by conventional methods [58]. A few years ago it was estimated that less than $0.1 \%$ of the world's totally or partially edentulous population had been treated with implants [59]. In April 2005, the largest implant company proudly proclaimed that 3 million patients had been treated with their implants as of that date, undoubtedly an impressive number. However, as this company is said to cover one third of the market, the total number of implant-treated patients would be about 10 million. If we very conservatively assume that $10 \%$ of the world's population of 6 billion is partially or totally edentulous, the proportion of those who have had implant treatment would be $1.7 \%$. This is, of course, pure conjecture as there are no reliable epidemiological data on dental/oral implants, but taking the estimate further, it could be assumed that those who have had the benefit would, in any case, represent only the economically fortunate ones. Even in the absence of evidence, it is most probable that, over the next few decades, the great majority of people with complete or partial edentulism will continue to receive conventional prosthodontic treatment or none at all.

\section{New Materials and Techniques}

Biocompatibility, aesthetics, reliability, longevity and stability are central to the search for optimal dental restorative materials. The metal-ceramic crown, introduced in the 1960s, has proven to have favourable long-term prospects. By virtue of their versatility, metal-ceramic crowns will undoubtedly continue to have an important place in future prosthodontic practice. Various factors, such as environmental aspects, fear of possibly toxic components in some older, traditional materials, and a strongly growing interest in aesthetics have prompted a rapid introduction of new materials. Titanium, well-proven as a biocompatible implant material, is also being used for crowns, both cast and spark-eroded, the latter technique again illustrating the expanding technological base of the discipline. The veneering of ceramic to titanium presented some early problems, but is showing promise in being overcome with new surface treatments [60].

The use of ceramics (in an unsupported, metal-free fashion) as a restorative material has increased substantially in the past two decades. Among other things, this trend can be attributed to the development of 'adhesive prosthodontics', or the ability to effectively bond metalfree ceramic restorations to tooth structure using acidetching techniques and adhesive cements. An example of the use of the adhesive technique is porcelain veneers, which have demonstrated successful results over at least 10 years [61].

The survival of older ceramic materials was not satisfactory because of low fracture toughness. Alumina and more recently zirconia have been used to improve the mechanical properties or to be used in combination with ceramics. However, the aesthetic properties of these newer materials are not fully acceptable and they need to be veneered with an appropriate ceramic to become ceramoceramic restorations [62]. As with other new materials, even medium-term follow-up data are lacking, yet cautious optimism about future improvements of ceramic materials would not be unreasonable. 
Innovations in technology too have influenced the fabrication of prosthodontic restorations over the past decades. Casting procedures have been optimized and CAD/CAM systems have been developed for fabricating both metal and ceramic single crowns, and fixed partial dentures for natural teeth as well as for implant superstructures. Refinements of these technologies by the increasing number of manufacturers involved in this field are cause for expecting rapid developments and innovations in the future.

Another new material combination of prosthodontic interest is fibre-reinforced composites that can be used for single and multiple tooth restorations as well as for treatment of worn dentitions. The clear advantage is their relative simplicity. A 5-year clinical follow-up has revealed a $90 \%$ functional survival rate for such fixed partial dentures [63]. If such promising results can be reproduced in other centres, fibre-reinforced composites may become an attractive alternative as they are less expensive than other materials and technologies used today.

\section{Implant Prosthodontics}

One obstacle to the wider use of implant-supported restorations is the economic aspect. Implant treatment, as with other high-technology dental methods, is expensive, which limits its use to relatively few people. Although efforts to improve implant treatment with new methods and components are proceeding apace in many centres around the world, few of them seem to be focused on the important issue of making it more affordable. A relatively low-cost alternative to implant-supported fixed prostheses, an overdenture supported by two implants, has been shown to improve mastication, speech, quality of life and even nutrition, compared to complete dentures. It has, therefore, been proposed that implant overdentures should become the standard of care for edentulous patients, particularly in the mandible, which usually presents the most critical of denture problems [64]. Whether or not an even more economically viable minimum standard of care can be developed for a single implant overdenture remains to be seen.

When economics permit, the choice of a fixed implantsupported restoration versus an implant overdenture in the treatment of the edentulous mandible varies greatly among prosthodontists within and among countries [65], yet preferences seem to be more dentist than patient determined. A strong contribution to this ongoing debate is the finding in a recent study that the mandibular implant overdenture is a less expensive treatment compared to the fixed implant prosthesis, which will also be the case in the long term [66].

Based on documented successful outcomes in many cases as well as efficient marketing by numerous companies, the strong interest of both patients and dentists will guarantee a continuing growth of implant treatment in dentistry. It has been calculated that the annual increase in the implant market has been around $15 \%$ over the last few years, with no decline expected in the near future [67].

New implant designs and altered surface properties are being rapidly developed and launched. However, they are often advertised and marketed before adequate tests have been performed. This is a cause for concern and needs better control in the future. In this regard, developments in the near future can be expected to include so-called bio-active surfaces and additives, as well as electrical and electromagnetic treatments that stimulate bone growth. Quality control systems will be used routinely for a better understanding of implant failures. Looking at the longterm perspective, however, it might be speculated that the interest in dental implants may abate as increased knowledge of human genetics and tissue engineering open the possibility of in vivo growth of teeth, perhaps making implants obsolete [68].

\section{The Future of Prosthodontic Research}

It has repeatedly been stated that the reporting of prosthodontic research is often of poor quality when assessed according to the criteria of evidence-based medicine/dentistry/practice. It may be of some comfort to prosthodontists that this state of affairs is not unique to the discipline, with most articles in the other dental specialties as well as in medicine equally demonstrating poor quality in the reporting of methodology and trial conduct $[53,69]$. This does not mean that all research is necessarily of poor quality; rather, it is the reporting that must be improved to facilitate proper interpretation of results. There remain many controversial issues in prosthodontics that need systematic and well-controlled study if they are to be resolved.

Implant research will continue to be the focus of interest in most laboratories and clinics. Topics for scientific investigation include causes of implant failure, the importance of modification of implant design and surface characteristics, comparisons among different brands, impact on patients with implant treatment or cost-effectiveness aspects. As in other areas of prosthodontics, there are many questions that remain to be answered by proper research on implant-supported prostheses. This dilem- 
ma has been commented on in the following way: 'If prospective, controlled clinical trials are required to answer these questions, they will never be answered; the questions are too many, too complex and maybe too expensive to answer in this way' [70]. This may seem somewhat pessimistic, but it is probably a realistic view. Nevertheless, there is a need for improved planning and design of studies and stricter presentation of the results according to current recommendations.

The current preoccupation with implants must not exclude research on conventional prosthodontics, as this will undoubtedly continue to be the predominant treatment alternative in the foreseeable future. Research in this area is to be encouraged to develop evidence-based clinical practice guidelines. An analysis of existing questions and of the formulation of current relevant research strategies in prosthodontics was published following a recent international symposium [71].

\section{Prosthodontic Education}

Developments in prosthodontics continue to be very rapid, not only in response to newer technologies, on the 'supply' side, but also to powerful social realities, such as consumerism, on the 'demand' side. The curricula of educational programmes must be flexible to make the necessary revisions easier, and preferably pro-active. In the new era of evidence-based practice, education at both the undergraduate and postgraduate levels must more strongly emphasize the scientific basis of prosthodontics. Psychosocial dimensions and quality-of-life aspects of patient care should be introduced into the undergraduate curriculum. Even though, in a global perspective, there is such diversity in the way prosthodontics is practiced, there need to be concerted and continuous efforts to harmonize dental education internationally. This should not be with the purpose of achieving uniformity particularly in curricular content, but rather to bring about better and more equitable qualities of care for the different regions of the world.

\section{The Future of the Prosthodontic Literature}

As pointed out earlier, the literature on implant prosthodontics has been increasing exponentially whereas other parts of the prosthodontic literature have diminished during the last two decades (fig. 3). Should this trend continue unabated, then there would be no literature on conventional prosthodontics within 20 years. This will, of course, not happen. Conventional prosthodontics will maintain an important role in dentistry, and related clinical and other research will certainly continue to be per- formed. Something as revolutionary as osseo integrated implants might happen in dentistry during the next few years and usher in as dramatic a change in clinical prosthodontics, research and the literature as did implants. After some false starts, the promise that CAD/CAM technology held when it was first introduced a number of years ago is beginning to show the levels of predictability and clinical efficiency demanded by today's practitioners. Even if such progress in CAD/CAM technology cannot be equated with osseo integration in terms of its contribution to alleviating people's functional disabilities, it certainly signifies advancement in another dimension, that of the process of care, an aspect important in its own right.

The Internet is changing traditional methods of disseminating information through journals and books. It has been suggested that digital publishing will change the forms of scientific communication as much as the art of printing did long ago. Many journals are already available online besides their paper versions, and some believe that electronic journals will gradually replace printed journals. Another growing trend is the number of journals that present their material as open access journals, free fulltext versions. This sounds attractive but may also entail problems and risks, something that is being urgently discussed among researchers, editors and publishers. One risk may be the weakening of the peer review system due to publishers striving for more rapid publication. Another is the publishers' temptation to publish articles that will attract attention in the mass media rather than in the scientific community [19].

Looking at the short-term perspective of perhaps one or two decades, it can be predicted that printed paper versions of scientific journals and textbooks will prevail, but in the longer term, momentous changes in the provision and dissemination of the prosthodontic literature are probable - but clearly not only so in the prosthodontic literature.

\section{Conclusions}

The changes in the discipline of prosthodontics over the last few decades, largely as a result of developments of new materials and methods, but also of prevention and improved dental health, have been momentous. Such developments, and probably some new initiatives as well, will most certainly continue to occur.

The revolution of dental implants, as well as other newer technologies, of which adhesive, high-strength ce- 
ramic and CAD/CAM technologies are notable examples, are in various stages of establishing themselves as part of 'mainstream' prosthodontics. While such developments have led to substantial changes in clinical prosthodontics, education in many respects seems to lag behind. Nevertheless, a concentration on advancing high technology in prosthodontics and related areas is likely to continue in many centres.

In most parts of the world, however, including large sectors within even the wealthiest of countries, conven- tional prosthodontic treatment, including removable dentures, will continue to play an essential role in everyday dentistry, partly reflecting sociopolitical disparities. How the prosthodontic profession will respond to this macroperspective is not easy to foretell. Whatever happens, it should at least be hoped that these factors are reflected in the future development of education and research in prosthodontics - even if available data and current trends do not convincingly point yet in this direction.

\section{References}

1 Levin B: 'The 28-tooth syndrome' - Or should all teeth be replaced? Dent Surv 1974;50:47.

2 Käyser AF: Teeth, tooth loss and prosthetic appliances; in Öwall B, Käyser AF, Carlsson GE (eds): Prosthodontics - Principles and Management Strategies. London, Mosby-Wolfe, 1996, pp 35-48.

-3 Jokstad A, Ørstavik J, Ramstad T: A definition of prosthetic dentistry. Int J Prosthodont 1998; 11:295-301.

4 The Academy of Prosthodontics: The glossary of prosthodontic terms, 7th edition. J Prosthet Dent 1999;81:41-110.

5 Öwall B, Käyser AF, Carlsson GE: Prosthodontics around the world; in Öwall B, Käyser AF, Carlsson GE (eds): Prosthodontics - Principles and Management Strategies. London, Mosby-Wolfe, 1996, pp 9-19.

6 Zarb GA, Anderson JD, Fenton AH: Decisionmaking in prosthodontics; in Öwall B, Käyser AF, Carlsson GE (eds): Prosthodontics - Principles and Management Strategies. London, Mosby-Wolfe, 1996, pp 125-134.

7 Pilot T: Economic perspectives on diagnosis and treatment planning in periodontology. $\mathrm{J}$ Clin Periodontol 1986;13:889-893.

>8 Österberg T, Carlsson GE, Sund V: Trends and prognoses of dental status in the Swedish population: analysis based on interviews in 1975 to 1997 by Statistics Sweden. Acta Odontol Scand 2000;58:177-182.

$\checkmark 9$ Steele JG, Treasure E, Pitts NB, Morris J, Bradnock G: Total tooth loss in the United Kingdom in 1998 and implications for the future. Br Dent J 2000; 189:598-603.

10 Pine CM, Pitts NB, Steele JG, Nunn JN, Treasure E: Dental restorations in adults in the UK in 1998 and implications for the future. $\mathrm{Br}$ Dent J 2001;190:4-8.

$>11$ Nunn J, Morris J, Pine C, Pitts NB, Bradnock G, Steele JG: The condition of teeth in the UK in 1998 and implications for the future. $\mathrm{Br}$ Dent J 2000;189:639-644.

$>12$ Käyser AF: Shortened dental arches and oral $>23$ function. J Oral Rehabil 1981;8:457-462.
13 Witter DJ, van Palenstein Helderman WH, Creugers NHJ, Käyser AF: The shortened dental arch concept and its implications for oral health care. Community Dent Oral Epidemiol 1999;27:249-258.

14 Creugers NHJ, Kreulen CM: Systematic review of 10 years of systematic reviews in prosthodontics. Int J Prosthodont 2003;16: 123-127.

15 Glantz P-O, Nilner K, Jendresen MD, Sundberg H: Quality of fixed prosthodontics after twenty-two years. Acta Odontol Scand 2002; 60:213-218.

16 Vermeulen AHBM, Keltjens HMAM, van't Hof MA, Käyser AF: Ten-year evaluation of removable partial dentures: survival rates based on retreatment, not wearing and replacement. J Prosthet Dent 1996;76:267-272.

17 Brånemark P-I: Osseointegration and its experimental background. J Prosthet Dent 1983; 50:399-410.

18 Zarb GA: Introduction to osseointegration in clinical dentistry. J Prosthet Dent 1983;49: 824.

19 Carlsson GE: Changes in the prosthodontic literature 1966 to 2042. J Can Dent Assoc 2005; 71:328. http://www.cda-adc.ca/jcda/vol-71/ issue-5/328.html.

20 Becker MJ: Ancient 'dental implants': a recently proposed example from France evaluated with other spurious examples. Int J Oral Maxillofac Implants 1999;14:19-29.

21 Brånemark P-I, Hansson BO, Adell R, Breine U, Lindström J, Hallén O, Öhman A: Osseointegrated Implants in the Treatment of the Edentulous Jaw: Experience from a 10-Year Period. Stockholm, Almqvist \& Wiksell Int, 1977.

22 Ekelund J-A, Lindquist LW, Carlsson GE, Jemt T: Implant treatment in the edentulous mandible: a prospective study on Brånemark system implants over more than 20 years. Int J Prosthodont 2003;16;602-608.

23 Owen P: Appropriatech: prosthodontics for the many, not just for the few. Int $\mathrm{J}$ Prosthodont 2004; 17:261-262.
24 Feine JS, Awad MA, Lund JP: The impact of patient preference on the design and interpretation of clinical trials. Community Dent Oral Epidemiol 1998;26:70-74.

25 Omar R: The evidence for prosthodontic treatment planning for older, partially dentate patients. Med Princ Pract 2003; 12(suppl 1):3342.

26 Narby B, Kronström M, Söderfeldt B, Palmqvist S: Prosthodontics and the patient: what is oral rehabilitation need? Conceptual analysis of need and demand for prosthodontic treatment. 1. Conceptual analysis. Int J Prosthodont 2005; 18:75-79.

27 Elias AC, Sheiham A: The relationship between satisfaction with mouth and number and position of teeth. J Oral Rehabil 1998;25: 649-661.

28 Mojon P, Thomason JM, Walls AWG: The impact of falling rates of edentulism. Int J Prosthodont 2004; 17:434-440.

29 Douglas CW, Shih A, Ostry L: Will there be a need for complete dentures in the United States in 2020? J Prosthet Dent 2002;87:5-8.

30 Steele JG, Ayatollahi SMT, Walls AWG, Murray JJ: Clinical factors related to reported satisfaction with oral function amongst dentate older adults in England. Community Dent Oral Epidemiol 1997;25:143-149.

31 Kanatani M, Watanabe K, Miyakawa O: Number projection of bridges and dentures for elderly and dependent elderly people. J Jpn Prosthodont Soc 2001;45:227-237.

32 Ettinger RL: Attitudes and values concerning oral health and utilization of services among the elderly. Int Dent J 1992;42:373-384.

-33 Österberg T, Carlsson GE, Sund V, Fyhrlund A: Prognosis of and factors associated with dental status in the adult Swedish population 1975-1989. Community Dent Oral Epidemiol 1995;23:232-236.

34 Green BL, Person S, Crowther M, Frison S, Shipp M, Lee P, Martin M: Demographic and geographic variations of oral health among African Americans based on NHANES III. Community Dent Health 2003;20:117-122. 
-35 Brunton PA, Vrihoef T, Wilson NHF: Restorative care and economic wealth: a global perspective. Int Dent J 2003;53:97-99.

- 36 Hobdell MH, Oliveira ER, Bautista R, Myburgh NG, Lalloo R, Narendran S, Johnson NW: Oral disease and socio-economic status (SES). Br Dent J 2003;194:91-96.

- 37 Lalloo R, Myburgh NG, Hobdell MH: Dental caries, socio-economic development and national oral health policies. Int Dent J 1999;49: 196-202.

- 38 Enwonwu CO: Socio-economic factors in dental caries prevalence and frequency in Nigerians. Caries Res 1974;8:155-171.

- 39 Naidoo S, Chikte UM, Moola H, Steyn K: Perceptions of oral health: the South African Demographic and Health Survey of 1998. S Afr Dent J 2001;56:505-510.

-40 Mofidi M, Rozier R: Problems associated with access to dental care for Medicaid-insured children: what caregivers think. Am J Public Health 2002;92:53-58.

-41 Chikte UME, Gilbert L, Brand AA, Lewis HA: Racial classification in dental literature: is it always necessary? S Afr Dent J 1989;44:337339.

42 WHO Expert Committee: Recent advances in oral health. WHO Techn Rep Ser 826. Geneva, WHO, 1992.

43 Omar R: Reappraising prosthodontic treatment goals for older, partially dentate people. II. Case for a sustainable dentition? S Afr Dent J 2004;228-237.

-44 Sarita PTN, Witter DJ, Kreulen CM, van't Hof MA, Creugers NHJ: Chewing ability of subjects with shortened dental arches. Community Dent Oral Epidemiol 2003;31:328-324.

-45 Sarita PTN, Kreulen CM, Witter DJ, van't Hof MA, Creugers NHJ: A study of occlusal stability in shortened dental arches. Int J Prosthodont 2003; 16:375-380.

-46 Sarita PTN, Kreulen CM, Witter DJ, Creugers NHJ: Signs and symptoms associated with temporomandibular disorders in adults with shortened dental arches. Int J Prosthodont 2003;16:265-270.

47 Wassell RW, Steele JG: Considerations when planning occlusal rehabilitation: a review of literature. Int Dent J 1998;48:571-581.
48 Tangerud T, Carlsson GE: Jaw registration and occlusal morphology; in Karlsson S, Nilner K, Dahl B (eds): A Textbook of Fixed Prosthodontics - The Scandinavian Approach. Stockholm, Gothia, 2000, pp 209-230.

49 American Dental Association: Future of Dentistry - Executive Summary. Chicago, American Dental Association, Health Policy Resources Center, 2002.

50 Van Palenstein Helderman W: Priorities in oral health care in non-EME countries. Int Dent J 2002;52:30-34.

51 WHO: Primary health care - Report on the international conference on primary health care, Alma Ata, USSR, September 1978. Geneva, WHO, 1978.

-52 Hujoel PP, Löe H, Anerud A, Boysen H, Leroux BG: Forty-five-year tooth survival probabilities among men in Oslo, Norway. J Dent Res 1998;77:2020-2027.

53 Jokstad A, Esposito M, Coulthard P, Worthington HV: The reporting of randomised controlled trials in prosthodontics. Int J Prosthodont 2002;15:230-242.

- 54 Jokstad A, Braegger U, Brunski JB, Carr AB, Naert I, Wennerberg A: Quality of dental implants. Int Dent J 2003;53(suppl 2):409-443.

55 Öwall B, Carlsson GE, Glimstedt B, Hermerén G, Nilner K, Scholander S: Esthetic and cosmetic dentistry: new and unique or a development of old methods? (In Swedish with an English summary). Tandläkartidningen 2005;97: 46-52.

56 MacEntee M: Prosthodontics: have we misjudged the cause and lost direction? Int $\mathrm{J}$ Prosthodont 2005;18:185-187.

57 Owen CP: In search for the minimum acceptable procedures for constructing conventional complete dentures: a Delphi survey. Proc 11th Meet Int Coll Prosthodontists, Crete, May 2528, 2005, p 58.

58 Taylor TD: The changing face of implant dentistry. Int J Oral Maxillofac Implants 2003;18: 793.

59 Carlsson GE: Clinical morbidity and sequelae of treatment with complete dentures. J Prosthet Dent 1998;79:17-23.
60 Al-Hussaini I, Al-Wazzan K: Effect of surface treatment on bond strength of low-fusing porcelain to commercially pure titanium. J Prosthet Dent 2005;94:350-356.

61 Peumans M, van Meerbeek B, Lambrechts P, Vanherle G: Porcelain veneers: a review of the literature. J Dent 2000;28:163-177.

62 Belser U: Metal-ceramic and ceramo-ceramic restorations: critical appraisal and clinical perspectives. Proc 11th Meet Int Coll Prosthodontists, Crete, May 25-28, 2005.

63 Vallitu PK: Survival rates of resin-bonded, glass fiber-reinforced composite fixed partial dentures with a mean follow-up of 42 months: a pilot study. J Prosthet Dent 2004;91:241246.

64 Feine JS, Carlsson GE (eds): Implant Overdentures - The Standard of Care for Edentulous Patients. Chicago, Quintessence, 2003.

65 Carlsson GE, Kronström M, de Baat C, Cune M, Davis D, Garefis P, Heo SJ, Jokstad A, Matsuura M, Närhi T, Ow R, Pissiotis A, Sato $H$, Zarb G: A survey of the use of mandibular implant overdentures in 10 countries. Int $\mathrm{J}$ Prosthodont 2004; 17:211-217.

66 Attard NJ, Zarb GA, Laporte A: Long-term treatment costs associated with implant-supported mandibular prostheses in edentulous patients. Int J Prosthodont 2005; 18:117-123.

67 Carlsson GE: Future directions; in Feine JS, Carlsson GE (eds): Implant Overdentures The Standard of Care for Edentulous Patients. Chicago, Quintessence, 2003, pp 145-154

68 Albrektsson T, Wennerberg A: The impact of oral implants - Past and future, 1966-2042. J Can Dent Assoc 2005;71:327. http://www.cdaadc.ca/jcda/vol-71/issue-5/327.html.

69 Sjögren P, Halling A: Quality of reporting randomised clinical trials in dental and medical research. Br Dent J 2002;192:100-103.

70 Taylor TD: Research directions in implant prosthodontics. Int J Prosthodont 2000;13: 270-271

-71 Zarb GA, MacEntee M, Anderson JD (eds): On biological and social interfaces in prosthodontics - Proceedings of an international symposium, November 3-6, 2002. Int J Prosthodont 2003;16(suppl):7-90. 